\title{
ANALISIS KEBUTUHAN PENGEMBANGAN MEDIA PEMBELAJARAN INTERAKTIF BERBASIS ADOBE FLASH CS6
}

\author{
Laila Raudatul Fauziah, Nizwardi Jalinus, Wakhinuddin S \\ Universitas Negeri Padang \\ raudatulfauriab19@gmail.com
}

\begin{abstract}
This study aims to describe the results of the needs analysis for the development of learning media based on Adobe Flash CS6. This research is a qualitative descriptive

Received: study using survey methods to identify the needs of students and teachers in learning April 02 2020 assessment. In this study, needs analysis refers to the achievement of student learning outcomes, problems faced by students, and the media needed in the learning

Revised: assessment process. This research uses observation and interview methods in collecting

May $14^{\text {th }} 2020$ data. Observations and interviews were conducted for grade X students of basic graphic design subjects at SMKN 8Padang. The results showed that: 1) completeness

Accepted: of student learning 2) Interactive learning media needed on computer subjects and

June $03^{\text {th }} 2020$ basic networks. The results of this study concluded that students need interactive learning media in learning activities. Thus, this research was used in designing learning based on Adobe Flash CS6.
\end{abstract}

Keywords: $\quad$ Needs Analisys; Interactive Learning Media; Adobe Flash CS6

\section{PENDAHULUAN}

Saat ini Indonesia menghadapi era Revolusi Industri 4.0 (RI 4.0). Untuk menghadapi era RI 4.0 para pelaku pendidikan harus sigap terhadap berbagai perubahan. Pendidikan 4.0 bertujuan untuk mempersiapkan lulusan untuk kehidupan masa depan dan pekerjaan yang dicapai oleh RI 4.0 di mana lebih banyak teknologi akan menggantikan orang-orang di divisi kegiatan tertentu, pendidikan harus memanfaatkan informasi dan kemampuan terkait yang tidak dapat digantikan oleh teknologi. Perubahan itu menghasilkan pendidikan 4.0 yang berfokus pada pengembangan pendidikan dan keterampilan telah membuat pembelajaran di masa depan lebih dikustomisasi, cerdas, portabel, mendunia dan virtual. ${ }^{1}$ Untuk menghadapi era RI 4.0 diperlukan pendidikan yang mampu menghasilkan generasi kreatif, inovatif, dan kompetitif dan memiliki keterampilan berpikir kritis, pengetahuan dan kemampuan literasi digital, literasi informasi, literasi media dan menguasai teknologi informasi dan komunikasi.

Salah satu kemampuan yang dibutuhkan dalam era RI 4.0 adalah literasi digital dimana SMK sebagai salah satu sekolah yang menyiapkan lulusan yang memiliki komptensi dibidang digital. SMK memiliki mata pelajaran Dasar Desain Grafis yang mana mata pelajaran ini merupakan langkah awal mempersiapkan lulusan dengan kompetensi dibidang desain grafis berbasis digital.

Dalam perkembangan pendidikan 4.0 saat ini, guru perlu memiliki kemampuan mengelola informasi. Pemanfaatan media, pemilihan metode, sistem penilaian dan penggunaan sarana dan prasarana yang tepat sangat dibutuhkan. Media pembelajaran yang baik yaitu media itu dapat

\footnotetext{
${ }^{1}$ Sumitra Nuanmeesri and Saran Jamornmongkolpilai, "The Development of the Virtual Learning Media of the Sacred Object Artwork.," Turkish Online Journal of Educational Technology-TOJET 17, no. 1 (2018): 197-209.
} 
meningkatkan minat belajar peserta didik. Media pembelajaran dapat disajikan secara tekstual, animasi, video, dan gambar. Perpaduan penyajian tersebut diharapkan lebih memotivasi siswa dan tidak membosankan bagi siswa. Dalam melaksanakan proses pembelajaran perlu diperhatikan pemanfaatan media. Selain gagasan guru perlu adanya unsur-unsur yang menunjang proses komunikasi yang efektif. Saat ini teknologi komputer, komunikasi internet, situs web, dan jejaring sosial memiliki peran dalam membantu pembelajaran dalam berbagai aspek. Penggunaan media pembelajaran yang tepat lebih diperlukan karena media akan membantu proses pembelajaran menjadi lebih efektif. ${ }^{2}$

Media digunakan agar pesan lebih jelas dan mengatasi keterbatasan ruang, tenaga, waktu dan daya indra sehingga timbullah motivasi belajar siswa. Dengan media terjadi interaksi langsung antara siswa dengan sumber belajar dan siswa bisa belajar mandiri sesuai dengan kemampuan yang dimilikinya ${ }^{3}$. Manfaat media pembelajaran yaitu bisa membuat siswa tertarik untuk belajar dan siswa termotivasi sehingga mudah memahami materi, serta siswa tidak merasa bosan dengan adanya variasi metode mengajar ${ }^{4}$.

Media didefinisikan sumber belajar yang dapat meransang peserta didik untuk belajar. Salah satu sarana pembelajaran multimedia yaitu CD Multimedia Interaktif ${ }^{5}$. CD Interaktif digunakan dalam pembelajaran agar pemhaman siswa lebih meningkat. CD Interaktif memberikan manfaat kepada setiap siswa. Karena sifatnya yang interaktif, CD interaktif sangat cocok untuk sebagai media pembelajaran. Dapat disimpulkan media ini bersifat interaktif dan terdapat berbagai media yang digabung menjadi satu media yaitu meliputi suara, animasi, video, teks dan grafis.

Berdasarkan hasil observasi pada Desember 2019, proses pembelajaran di SMK Negeri 8 Padang belum menggunakan media pembelajaran yang optimal. Guru masih menggunakan metode ceramah dan media presentasi berupa power point. Kurangnya waktu untuk menyampaikan materi pembelajaran dan waktu untuk praktik juga dirasakan guru. Hal ini terjadi karena siswa sering mengulang-ulang pertanyaan sehingga waktu banyak terpakai untuk itu. Kurangnya pemahaman siswa terhadap materi pembelajaran berdampak pada hasil belajar siswa. Berdasarkan nilai siswa kelas $\mathrm{X}$ tahun ajaran 2019/2020 semester ganjil mata pelajaran Dasar Desain Grafis diperoleh hasil belajar yang dapat dilihat pada tabel 1 dibawah ini :

Tabel 1. Hasil Belajar Siswa kelas X tahun ajaran 2019/2020 semester ganjil

\begin{tabular}{|l|l|l|l|l|}
\hline No & Kelas & Jumlah Siswa & Tidak Kompeten & Kompeten \\
\hline 1 & X TKJ 1 & 36 & 15 & 21 \\
\hline 2 & X TKJ 2 & 35 & 11 & 24 \\
\hline
\end{tabular}

2 Aida Aryani Shahroom and Norhayati Hussin, "Industrial Revolution 4.0 and Education," International Journal of Academic Research in Business and Social Sciences 8, no. 9 (2018): 314-319.

${ }^{3}$ Drs Daryanto, "Media Pembelajaran," Yogjakarta, Gava Media (2010).

${ }^{4}$ Nana Sudjana and Ahmad Rivai, "Media Pengajaran Bandung," S inar Baru Algesindo (2013).

${ }^{5}$ Dkk Rusman and M Pd, "Model-Model Pembelajaran," Raja Grafindo, Jakarta (2012). 
Sumber : Guru Mata Pelajaran Dasar Desain Grafis SMK N 8 Padang.

Hasil belajar siswa pada mata pelajaran dasar desain grafis masih bayak yang belum mencapai batas ketuntasan. Media pembelajaran yang mendukung pemahaman konseptual dalam proses pembelajaran sesuai dengan permasalahan yang ada salah satunya yaitu dengan cara pengembangan media pembelajaran interaktif dengan menggunakan aplikasi-aplikasi yang mendukung dalam membuat media tersebut. Aplikasi tersebut harus didukung dengan banyak fitur media seperti video, penambahan animasi, dan kuis untuk latihan siswa.

Dengan demikian, penggunaan media pembelajaran interaktif perlu dibuat untuk meningkatkan nilai siswa rendah. Satu perubahan yang sangat penting diterapkan dalam media pembelajaran. Perubahan dalam media pembelajaran dapat dilakukan dengan membuat media baru atau mengembangkan media yang ada. Pengembangan media pembelajaran dianggap penting karena kebutuhan siswa belajar media pembelajaran yang mendukung pembelajaran mandiri sehingga mereka tidak lagi tergantung tempat pembelajaran. Pengembangan media pembelajaran harus mampu menyajikan materi dan membuat siswa tidak terbatas dalam pembelajaran. Sehingga pembelajaran bisa dilakukan kapanpun dan dimanapun. Dengan media diharapkan untuk meminimalkan kegagalan dalam praktik dan meningkatkan hasil belajar siswa. Pengembangan media pembelajaran dalam meminimalkan masalah ini dapat memanfaatkan Media Pembelajaran Interaktif berbasis Adobe Flash CS6. Media ini bisa dijalankan di komputer dan di smartphone. Media juga mampu memberikan kebebasan kepada siswa dalam mengontrol kecepatan belajar. Media pembelajaran interaktif juga mampu memberikan kesempatan kepa siswa untuk berpartisipasi aktif meberikan respon ${ }^{6}$. Multimedia pembelajaran memiliki keunggulan diantaranya adalah: (1) mixed media, mengintegrasikan berbagai media konvensional yang ada kedalam satu jenis media interaktif.; (2) user control, memungkinkan pengguna untuk menelusuri materi ajar sesuai dengan kemampuan dan latar belakang pengetahuan yang dimilikinya?

Banyak jenis penelitian yang telah dilakukan dalam pengembangan media pembelajaran interaktif yang menghasilkan perubahan yang baik dan efektif untuk meningkatkan hasil pembelajaaran. Keuntungan dari media pembelajaran interaktif ini akan dikembangkan menjadi media pembelajaran. Dengan demikian, peneliti tertarik untuk melakukan penelitian tentang pengembanagn media pembelajaran berbasis Adobe Flash CS6 pada mata pelajaran Dasar Desain Grafis.

\footnotetext{
${ }^{6}$ Daryanto, "Media Pembelajaran."

${ }^{7}$ Rob Philips, "The Developer's Handbook to Interactive Multimedia (A Practical Guide for Educational Applications)," New York: Kogan Page, Ltd. https:// doi. org/10.1 1 (1997): 7898.
} 


\section{METODE}

Karena penelitian adalah tahap awal penelitian dan pengembangan $(R \& D)$, penelitian ini tidak terbatas untuk menganalisis kebutuhan dengan melakukan pengamatan. Penelitian ini melibatkan siswa kelas X Jurusan teknik komputer dan jaringan di SMKN 8 Padang. Ada 71 siswa yang berpartisipasi dalam memberikan pendapat tentang apa yang mereka butuhkan dalam kegiatan pembelajaran Dasar Desain Grafis. Selain itu, seorang guru Dasar Desain Grafis. Penelitian ini menggunakan metode penelitian deskriptif. Metode penelitian kualitatif adalah metode penelitian berdasarkan filosofi positivisme, yang digunakan untuk memeriksa populasi atau sampel tertentu; data penelitian dikumpulkan dengan menggunakan instrumen penelitian, analisis data kuantitatif atau statistik, dengan tujuan menguji hipotesis yang ditetapkan ${ }^{8}$. Data dikumpulkan melalui teknik observasi dan wawancara dengan instrumen dalam bentuk kuesioner. Kuesioner digunakan untuk mengetahui pendapat siswa terkait dengan kebutuhan media pembelajaran yang dikembangkan. Data yang diperoleh dari kuesioner dianalisis dan kemudian dirangkum dalam sebuah tabel. Data diperoleh dari penggunaan analisis kuesioner terhadap kebutuhan guru dan siswa.

Data yang diperoleh diproses dalam empat tahap: 1) pengumpulan data dari distribusi kuesioner. 2) tabulasi data untuk melihat kelas, sifat, jenis, dan frekuensi data. 3) Tabulasi data bertujuan untuk memfasilitasi membaca, mengategorikan, dan menganalisis data. 4) membuat interpretasi dari hasil analisis masalah dan pertanyaan peneliti, sehingga mereka dapat menarik kesimpulan.

\section{HASIL DAN PEMBAHASAN}

Analisis kebutuhan untuk pengembangan media pembelajaran interaktif pada mata pelajaran dasar desain grafis diperoleh melalui observasi dan wawancara. Pemantauan dilakukan oleh 71 siswa kelas X jurusan teknik komputer dan jaringan dan seorang guru dasar desain grafis pada semester JuliDesember 2019.

Berdasarkan hasil wawancara dengan guru dasar desain grafis standar proses dalam pembelajaran sudah cukup baik namun belum adanya penggunaan media yang bervariasi saat pembelajaran maupun ketika siswa belajar mandiri. Metode yang biasa digunakan dalam pembelajaran yaitu menggunakan metode ceramah, diskusi, penugasan dan demonstrasi dengan menggunakan media proyektor, powerpoint dan komputer. Guru mengatakan bahwa minat dan motivasi siswa tergantung dengan media yang digunakan dan situasi saat pembelajaran. Untuk alokasi waktu pembelajaran guru masih kekurangan waktu untuk menyampaikan materi dikelas. Sehingga perlu adanya media yang membantu siswa untuk belajar mandiri dirumah. Berdasarkan hasil wawancara dengan guru mata pelajaran dasar desain grafis dapat disimpulkan bahwa guru memiliki kendala dalam menggunakan

${ }^{8}$ R C Richey and J D Klein, "Design and Development Research: Methods, Strategies and Issues,(2007)” (New Jersey: Lawrence Erlbaum Associates, Publishers, n.d.). 
media yang bervariasi dan kurangnya waktu dalam proses pembelajaran disekolah. Oleh karena itu dibutuhkan sebuah media yang bisa membantu guru dan siswa. Siswa belum menggunakan media pembelajaran interaktif dalam proses pembelajaran. Pengembangan media pembelajaran interaktif terutama pada mata pelajaran dasar desain grafis. Penggunaan media pembelajaran sangat membantu siswa dalam kegiatan praktis di sekolah karena dilengkapi dengan animasi, gambar, dan tutorial. Pengembangan media pembelajaran berbasis Adobe Flash CS6 dilakukan dengan proses pengumpulan data seperti kurikulum, bahan ajar, dan materi dasar desain grafis. Oleh karena itu, pengamatan dilakukan pada siswa tentang masalah dan harapan menggunakan media dari pelajaran dasar desain grafis. Hasil penelitian pada siswa dalam bentuk data yang diperoleh ditunjukkan pada tabel 2.

Tabel 2

\begin{tabular}{|l|l|}
\hline No. & \multicolumn{1}{|c|}{ Analisis Pertanyaan } \\
\hline 1 & $70 \%$ siswa merasa senang belajar Dasar Desain Grafis \\
\hline 2 & $76 \%$ siswa merasa kekurangan waktu dalam menguasai materi desain grafis disekolah \\
\hline 3 & $59 \%$ merasa sulit memahami materi dasar desain grafis \\
\hline 4 & $96 \%$ siswa membutuhkan media dalam pembelajaran berupa teori maupun praktis \\
\hline 5 & $72 \%$ siswa merasa mudah dengan media yang berisikan audio, video dan animasi \\
\hline 6 & $92 \%$ siswa merasa termotivasi dengan penggunaan media \\
\hline 7 & $94 \%$ siswa merasa sangat membutuhkan media untuk berinteraksi \\
\hline 8 & $96 \%$ siswa membutuhkan keterbaharuan media dalam peembelajaran Dasar Desain \\
& Grafis \\
\hline 9 & $63 \%$ siswa mengalami kesulitas saat praktikum \\
\hline 10 & $82 \%$ siswa merasa mudah saat praktik dengan adanya media \\
\hline 11 & $85 \%$ siswa mampu menggunakan komputer dan smartphone \\
\hline
\end{tabular}

Hasil analisis kebutuhan siswa menunjukkan bahwa 59\% siswa kesulitan memahami materi dasar desain grafis dan 63\% siswa memiliki kesulitan saat praktikum. 85\% siswa memiliki dan mampu menggunakan teknologi ponsel cerdas, dan itu dapat digunakan dalam proses pembelajaran. Pemanfaatan teknologi informasi dan komunikasi dapat dilakukan dalam proses pembelajaran sebagai media pendamping bagi siswa dalam pembelajaran. Penggunaan media pembelajaran dalam pembelajaran adalah penting karena seiring dengan perkembangan teknologi akan mempengaruhi pengembangan proses pembelajaran praktikum. Produk yang dikembangkan adalah media pembelajaran interaktif berbasis Adobe Flash CS6. Media pembelajaran interaktif dengan format exe dan apk yang dapat dijalankan dikomputer dan android. Pengembangan media pembelajaran interaktif berbasis Adobe Flash CS6 melalui 4 fase: mendefinisikan, merancang, mengembangkan, dan 
mengimplementasikan. Tahap pertama adalah mendefinisikan. Melalui tahap ini, analisis kebutuhan diperoleh dalam pengembangan media pembelajaran interaktif berbasis Adobe Flash CS6. Perangkat lunak yang diperlukan dalam pengembangan media pembelajaran interaktif adalah Adobe Flash CS6. Perangkat keras yang diperlukan dalam penelitian ini adalah sistem operasi Windows 10, dan spesifikasi perangkat keras minimum yang dapat digunakan adalah prosesor 64-bit dan sistem operasi prosesor Intel ${ }^{\circledR}$ dengan dukungan untuk Intel ${ }^{\circledR}$ VT -x, Intel ${ }^{\circledR}$ EM64T (Intel ${ }^{\circledR}$ 64), dan Execute Disable (XD) Bit Function, 3GB RAM, dengan 2GB ruang disk yang tersedia. Penggunaan media ini dalam bentuk media pembelajaran yang bisa diinstal dikomputer dan smartphone. Penggunaan multimedia pembelajaran interaktif dalam kelas didukung dengan hasil penelitian yang dilakukan oleh Mayer, McCarthy dan Walton (1993) menyebutkan bahwa multimedia memberikan banyak manfaat yang dari penggunaannya ${ }^{9}$. Keuntungan belajar lebih besar 56\%, konsistensi belajar lebih baik $50-60 \%$ dan retensi konten $25-50 \%$ lebih tinggi ${ }^{10}$. Berdasarkan hasil penelitian-penelitian ini, maka multimedia pembelajaran dapat dikatakan sebagai media yang mempunyai potensi yang sangat besar dalam membantu proses pembelajaran. Analisis kebutuhan ini menunjukkan kebutuhan guru dalam meningkatkan kualitas media pembelajaran dan kebutuhan siswa untuk pembelajaran menggunakan media adalah perangkat bergerak, interaktif, dan mendukung kegiatan belajar.

\section{KESIMPULAN}

Penelitian ini bertujuan untuk mendeskripsikan hasil analisis kebutuhan dalam proses pengembangan media interaktif pada mata pelajaran dasar desain grafis. Berdasarkan hasil dan pembahasan penelitian ini, menunjukkan bahwa pengembangan media pembelajaran interaktif perlu dilakukan. Analisis kebutuhan menunjukkan bahwa guru perlu meningkatkan kualitas pembelajaran dan media pembelajaran. Selain itu, siswa memerlukan media penilaian yang aktif, bergerak, dan memanfaatkan teknologi sehingga mereka dapat membantu siswa dalam memahami materi dan menyelesaikan tugas-tugas. Berdasarkan studi pendahuluan dan hasil pengamatan dan wawancara, dapat disimpulkan dari penelitian ini adalah; 1) masih ada siswa yang belum mencapai skor KKM karena siswa belum maksimal dalam pembelajaran 2) Dalam pembelajaran belum ada media pembelajaran interaktif yang membantu siswa sehingga siswa mencapai KKM 3) Media interaktif perlu ditingkatkan dan dikembangkan di mata pelajaran dasar desain grafis.

\footnotetext{
${ }^{9}$ R Mayer, "Multimedia Learning, Prinsip-Prinsip, Dan Aplikasi (Terjemahan)" (Surabaya: ITS Press, 2009).

${ }^{10}$ Usha V Reddi and Sanjaya Mishra, "Educational Multimedia," A handbook for teacher-developers. New Delbi: CEMCA (2003).
} 


\section{DAFTAR PUSTAKA}

Daryanto, Drs. “Media Pembelajaran.” Yogjakarta, Gava Media (2010).

Mayer, R. "Multimedia Learning, Prinsip-Prinsip, Dan Aplikasi (Terjemahan)." Surabaya: ITS Press, 2009.

Nuanmeesri, Sumitra, and Saran Jamornmongkolpilai. "The Development of the Virtual Learning Media of the Sacred Object Artwork." Turkish Online Journal of Educational Technology-TOJET 17, no. 1 (2018): 197-209.

Philips, Rob. “The Developer's Handbook to Interactive Multimedia (A Practical Guide for Educational Applications)." New York: Kogan Page, Ltd. bttps:// doi. org/10.1 1 (1997): 7898.

Reddi, Usha V, and Sanjaya Mishra. "Educational Multimedia." A bandbook for teacher-developers. New Delhi: CEMCA (2003).

Richey, R C, and J D Klein. "Design and Development Research: Methods, Strategies and Issues,(2007).” New Jersey: Lawrence Erlbaum Associates, Publishers, n.d.

Rusman, Dkk, and M Pd. "Model-Model Pembelajaran.” Raja Grafindo, Jakarta (2012).

Shahroom, Aida Aryani, and Norhayati Hussin. "Industrial Revolution 4.0 and Education." International Journal of Academic Research in Business and Social Sciences 8, no. 9 (2018): 314-319.

Sudjana, Nana, and Ahmad Rivai. “Media Pengajaran Bandung." S inar Baru Algesindo (2013). 